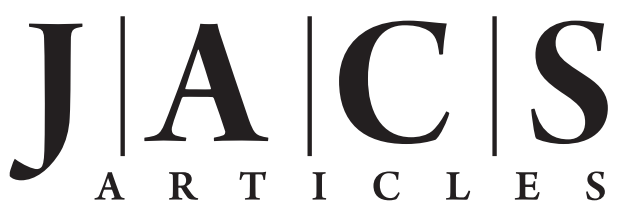

Published on Web 02/04/2010

\title{
Molecular Electrocatalysis for Oxygen Reduction by Cobalt Porphyrins Adsorbed at Liquid/Liquid Interfaces
}

\author{
Bin Su, ${ }^{\dagger, \varpi}$ Imren Hatay, ${ }^{\dagger, \perp}$ Antonín Trojánek, ${ }^{\ddagger}$ Zdeněk Samec, ${ }^{\ddagger}$ Tony Khoury, ${ }^{\S}$ \\ Claude P. Gros, ${ }^{\S}$ Jean-Michel Barbe, ${ }^{\S}$ Antoine Daina, " Pierre-Alain Carrupt, " and \\ Hubert H. Girault*, \\ Laboratoire d'Electrochimie Physique et Analytique, Ecole Polytechnique Fédérale de \\ Lausanne, Station 6, CH-1015 Lausanne, Switzerland, J. Heyrovský Institute of Physical \\ Chemistry of ASCR, v.v.i, Dolejškova 3, 18223 Prague 8, Czech Republic, Institut de \\ Chimie Moléculaire de l'Université de Bourgogne, ICMUB (UMR 5260), \\ BP 47870, 21078 Dijon Cedex, France, Department of Chemistry, Selcuk University, \\ 42031 Konya, Turkey, Section des Sciences Pharmaceutiques, Quai Ernest-Ansermet 30,
} CH-1211 Genève 4, Switzerland

Received October 5, 2009; E-mail: hubert.girault@epfl.ch

\begin{abstract}
Molecular electrocatalysis for oxygen reduction at a polarized water/1,2-dichloroethane (DCE) interface was studied, involving aqueous protons, ferrocene (Fc) in DCE and amphiphilic cobalt porphyrin catalysts adsorbed at the interface. The catalyst, (2,8,13,17-tetraethyl-3,7,12,18-tetramethyl-5- $p$-aminophenylporphyrin) cobalt(II) (CoAP), functions like conventional cobalt porphyrins, activating $\mathrm{O}_{2}$ via coordination by the formation of a superoxide structure. Furthermore, due to the hydrophilic nature of the aminophenyl group, CoAP has a strong affinity for the water/DCE interface as evidenced by lipophilicity mapping calculations and surface tension measurements, facilitating the protonation of the CoAP-O complex and its reduction by ferrocene. The reaction is electrocatalytic as its rate depends on the applied Galvani potential difference between the two phases.
\end{abstract}

\section{Introduction}

Molecular oxygen $\left(\mathrm{O}_{2}\right)$ reduction reaction $(\mathrm{ORR})$ is an important topic in biological and energy-related chemistry. ${ }^{1,2}$ However, it is a spin-forbidden process, which is kinetically slow at ambient temperature unless a catalyst is present. Nature has made the choice in aerobic organisms by evolving membranebound enzymes that contain a porphyrin substructure as catalysts. ${ }^{1,3-6}$ Inspired by their role in nature, a number of metalloporphyrins have been chemically synthesized. ${ }^{7-9}$ Their

† Ecole Polytechnique Fédérale de Lausanne.

J. Heyrovský Institute of Physical Chemistry of ASCR.

$\S$ Institut de Chimie Moléculaire de l'Université de Bourgogne.

${ }^{\perp}$ Selcuk University.

"I Section des Sciences Pharmaceutiques.

- Present Address: Institute of Microanalytical Systems, Department of Chemistry, Zhejiang University, Hangzhou 310058, China.

(1) Boulatov, R. In N4-Macrocyclic Metal Complexes; Zagal, J. H., Bedioui, F., Dodelet, J.-P., Eds.; Springer: New York, 2006; pp 136.

(2) Shukla, A. K.; Raman, R. K. Ann. Rev. Mater. Res. 2003, 33, 155168.

(3) Babcock, G. T. Proc. Natl. Acad. Sci. U.S.A. 1999, 96, 12971-12973.

(4) Babcock, G. T.; Wikstrom, M. K. F. Nature 1992, 356, 301-309.

(5) Sono, M.; Roach, M. P.; Coulter, E. D.; Dawson, J. H. Chem. Rev. 1996, 96, 2841-2887.

(6) Wikstrom, M. K. F. Nature 1977, 266, 271-273.

(7) Collman, J. P.; Boulatov, R.; Sunderland, C. J.; Fu, L. Chem. Rev. 2004, 104, 561-588.

(8) Kim, E.; Chufan Eduardo, E.; Kamaraj, K.; Karlin Kenneth, D. Chem. Rev. 2004, 104, 1077-1133.

(9) Zagal, J. H.; Paez, M. A.; Silva, J. F. In N4-Macrocyclic Metal Complexes; Zagal, J. H., Bedioui, F., Dodelet, J.-P., Eds.; Springer: New York, 2006; pp 41-75. catalytic activity has been investigated either electrochemically using the modified electrode methodology ${ }^{9-25}$ or chemically using molecular electron donors, such as ferrocene $(\mathrm{Fc})$ and its

(10) Anson, F. C.; Shi, C.; Steiger, B. Acc. Chem. Res. 1997, 30, 437444.

(11) Chang, C. J.; Deng, Y.; Nocera, D. G.; Shi, C.; Anson, F. C.; Chang, C. K. Chem. Commun. 2000, 1355-1356.

(12) Chang, C. J.; Loh, Z. H.; Shi, C.; Anson, F. C.; Nocera, D. G. J. Am. Chem. Soc. 2004, 126, 10013-10020.

(13) Collman, J. P. Acc. Chem. Res. 1977, 10, 265-272.

(14) Collman, J. P.; Boulatov, R.; Sunderland, C. J. In The Porphyrin Handbook; Kadish, K. M., Smith, K. M., Guilard, R., Eds.; Academic Press: San Diego 2003; Vol. 11, pp 1-49.

(15) Collman, J. P.; Chang, L. L.; Tyvoll, D. A. Inorg. Chem. 1995, 34, 1311-1324.

(16) Collman, J. P.; Denisevich, P.; Konai, Y.; Marrocco, M.; Koval, C.; Anson, F. C. J. Am. Chem. Soc. 1980, 102, 6027-6036.

(17) Collman, J. P.; Fu, L.; Herrmann, P. C.; Zhang, X. Science 1997, 275, 949-951.

(18) Collman, J. P.; Hutchison, J. E.; Lopez, M. A.; Tabard, A.; Guilard, R.; Seok, W. K.; Ibers, J. A.; L'Her, M. J. Am. Chem. Soc. 1992, 114, 9869-9877.

(19) Collman, J. P.; Marrocco, M.; Denisevich, P.; Koval, C.; Anson, F. C. J. Electroanal. Chem. Interfacial Electrochem. 1979, 101, 117-22.

(20) Deng, Y.; Chang, C. J.; Nocera, D. G. J. Am. Chem. Soc. 2000, 122, $410-411$.

(21) Durand, R. R., Jr.; Anson, F. C. J. Electroanal. Chem. Interfacial Electrochem. 1982, 134, 273-89.

(22) Shi, C.; Anson, F. C. Inorg. Chem. 1990, 29, 4298-4305.

(23) Shi, C.; Steiger, B.; Yuasa, M.; Anson, F. C. Inorg. Chem. 1997, 36, 4294-4295.

(24) Collman, J. P.; Wagenknecht, P. S.; Hutchison, J. E. Angew. Chem., Int. Ed. 1994, 33, 1620-1639.

(25) Le Mest, Y.; Inisan, C.; Laouenan, A.; L'Her, M.; Talarmin, J.; El Khalifa, M.; Saillard, J. Y. J. Am. Chem. Soc. 1997, 119, 6095-6106. 
derivatives, in homogeneous solutions. ${ }^{26-28}$ In the latter case, reduction of $\mathrm{O}_{2}$ by $\mathrm{Fc}$ in acidic solutions ${ }^{29-32}$ proceeds rather slowly, and the presence of a catalytic amount of metalloporphyrins can significantly accelerate the reaction rate. ${ }^{26-28}$

On the other hand, ORR is a proton-coupled electron transfer (PCET) reaction. When studying ORR on a solid electrode by amperometry, one measures the electron transfer rate, but it is not possible to control the proton transfer step by controlling the electrode potential. Electrochemistry at a liquid/liquid interface, also called interface between two immiscible electrolyte solutions (ITIES), has manifested itself recently as a unique approach to study PCET reaction with the possibility of locating protons in the aqueous phase and electron donors in the organic phase. ${ }^{33}$ In this work, proton-coupled oxygen reduction by $\mathrm{Fc}$ involving an amphiphilic cobalt porphyrin catalyst, (2,8,13,17-tetraethyl-3,7,12,18-tetramethyl-5- $p$-aminophenylporphyrin) cobalt(II) (CoAP), at a polarized water/1,2dichloroethane (DCE) interface is reported. CoAP serves as a redox catalyst like conventional cobalt porphyrins, activating $\mathrm{O}_{2}$ reduction via coordination with the cobalt(II) $\left(\mathrm{Co}^{\mathrm{II}}\right)$ center by the formation of a superoxide structure. Moreover, since CoAP is an amphiphilic molecule with a strong interfacial affinity, the proton-coupled oxygen reduction is an interfacial process. These two factors play together to account for the excellent electrocatalytic activity of CoAP, which is better than those previously reported for cobalt porphine (CoP) ${ }^{33}$ cobalt tetraphenylporphyrin (CoTPP), ${ }^{34}$ and cobalt octaethylporphyrin $\mathrm{Co}(\mathrm{OEP})^{35}$ that are not amphiphilic. The present system provides an example of interfacial molecular electrocatalysis for oxygen reduction combining the advantages of molecular catalyst and electrocatalysis because the ORR depends on the applied Galvani potential difference between the two phases.

\section{Experimental Section}

Chemicals. All chemicals were used as received without further purification. The aqueous solutions were prepared with ultrapure water $\left(18.2 \mathrm{M} \Omega \mathrm{cm}^{-1}\right)$. Ferrocene $(\mathrm{Fc}, 98 \%), 1,1^{\prime}$-dimethylferrocene (DFc, 97\%), ferrocenecarboxaldehyde (FcCA, 98\%), trifluoroacetic acid (TFA, 98\%), and lithium tetrakis(pentafluorophenyl)borate (LiTB) diethyl etherate were purchased from Aldrich. Lithium chloride anhydrous $(\mathrm{LiCl}, \geq 99 \%), \mathrm{NaI}(>99.5 \%)$, starch (from potatoes), tetramethylammonium chloride (TMACl, $>98.0 \%$ ), tetraethylammonium chloride ( $\mathrm{TEACl},>98.0 \%$ ), bis(triphenylphosphoranylidene)ammonium chloride $(\mathrm{BACl}, \geq 98 \%)$, and $1,2-$ dichloroethane (DCE, $\geq 99.8 \%$ ) were ordered from Fluka. Hydrochloric acid $(\mathrm{HCl}, 32 \%)$ was bought from Merck. Bis(triphenylphosphoranylidene)ammonium tetrakis(pentafluorophenyl)borate (BATB) was prepared as previously reported. ${ }^{36}$

(26) Fukuzumi, S.; Mochizuki, S.; Tanaka, T. Chem. Lett. 1989, 27-30.

(27) Fukuzumi, S.; Mochizuki, S.; Tanaka, T. Inorg. Chem. 1989, 28, 2459 65.

(28) Fukuzumi, S.; Okamoto, K.; Gros, C. P.; Guilard, R. J. Am. Chem. Soc. 2004, 126, 10441-10449.

(29) Bitterwolf, T. E.; Ling, A. C. J. Organomet. Chem. 1972, 40, C29C32.

(30) Prins, R.; Kortbeek, A. G. T. G. J. Organomet. Chem. 1971, 33, C33C34.

(31) Fomin, V. M. Russ. J. Gen. Chem. 2007, 77, 954-960.

(32) Fomin, V. M.; Shirokov, A. E.; Polyakova, N. G.; Smirnov, P. A Russ. J. Gen. Chem. 2007, 77, 652-653.

(33) Hatay, I.; Su, B.; Li, F.; Mendez, M. A.; Khoury, T.; Gros, C. P.; Barbe, J.-M.; Ersoz, M.; Samec, Z.; Girault, H. H. J. Am. Chem. Soc. 2009, 131, 13453-13459.

(34) Partovi-Nia, R.; Su, B.; Li, F.; Gros, C. P.; Barbe, J.-M.; Samec, Z.; Girault, H. H. Chem-Eur. J. 2009, 15, 2335-2340.

(35) Partovi-Nia, R. Ph.D. Thesis, EPFL, Lausanne, 2010.
Scheme 1. Electrochemical Cells Employed

Cell 1:

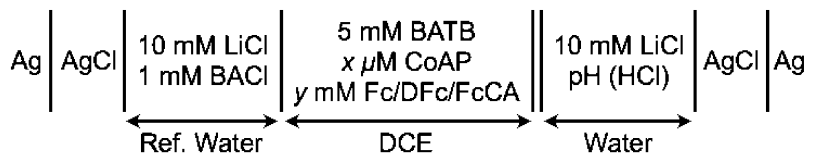

Cell 2:

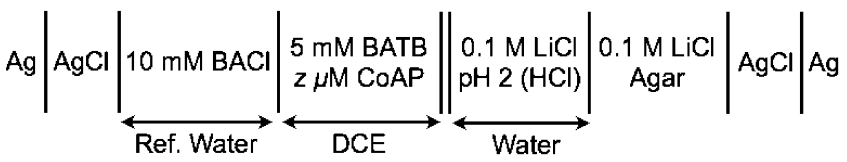

Electrochemical Measurements. All the electrochemical measurements were performed at ambient temperature $\left(23 \pm 2{ }^{\circ} \mathrm{C}\right)$. Cyclic voltammograms (CVs) at the water/DCE interface were obtained on a custom-built four-electrode system equipped with a DS335 synthesized function generator (Stanford Research System). A three-compartment glass cell featuring a cylindrical vessel was used, where the water/DCE interface with a geometric area of 1.53 $\mathrm{cm}^{2}$ was formed. Two platinum counter electrodes were respectively positioned in the aqueous and DCE phases to supply the current flow. The external potential was applied by means of two silver/ silver chloride $(\mathrm{Ag} / \mathrm{AgCl})$ reference electrodes, which were connected respectively to the aqueous and DCE phases by means of a Luggin capillary. The electrochemical cells used are illustrated in Scheme 1. The potential was converted to the Galvani potential difference $\left(\Delta_{\mathrm{o}}^{\mathrm{w}} \phi\right)$, based on cyclic voltammetric measurement of the reversible half-wave potential of the $\mathrm{TMA}^{+}$ion transfer $(0.160$ V). ${ }^{37}$ Measurements were carried out under aerobic conditions unless specified otherwise.

Surface Tension Measurements. Surface tension measurements were performed using the video-image pendant-drop method ${ }^{38,39}$ in a four-electrode all-glass cell, which was adapted from a spectroscopic cuvette $(10 \mathrm{~mm} \times 10 \mathrm{~mm})$. The cell was connected to a four-electrode potentiostat (PGSTAT 30, Eco-Chemie, Netherlands). The cell potential was changed stepwise ( $25 \mathrm{mV}$ per step, 25 s step time), and on each step the drop image was captured ( 24 $\mathrm{s}$ after the potential step change), and analyzed with the help of CAM101 System (KSV Instruments Ltd., Finland). Potential scale conversion was based on the reversible half-wave potential of the $\mathrm{TEA}^{+}$ion transfer. ${ }^{37}$ Measurements were carried out with airsaturated solutions.

Two-Phase Reactions Controlled by the Distribution of a Common Ion. Two-phase reactions were performed in small glass flasks with a volume of $10 \mathrm{~mL}$. A flask was filled first with $2 \mathrm{~mL}$ of DCE solution containing reactants ( $\mathrm{Fc}, \mathrm{CoAP})$, followed by the addition of $2 \mathrm{~mL}$ of aqueous solution containing $10 \mathrm{mM} \mathrm{HCl}$. The salts of the common ion $\left(\mathrm{TB}^{-}\right)$, LiTB and BATB, were added in the same concentration of $5 \mathrm{mM}$ to the aqueous and DCE phases, respectively. After stirring and further waiting for the clear separation of two phases, the aqueous and organic solutions were isolated from each other. The organic phase was directly subjected to the UV-visible spectroscopic measurement (Ocean Optical CHEM2000 spectrophotometer, quartz cuvette with a path length $10 \mathrm{~mm}$ ), while the aqueous phase was first treated by excess $\mathrm{NaI}$ (equivalent to $0.1 \mathrm{M}$ ) prior to the $\mathrm{UV}$-visible spectroscopic measurement.

Lipophilicity Mapping. The lipophilicity distribution around molecules was characterized by the molecular lipophilicity potential

(36) Su, B.; Abid, J.-P.; Fermin, D. J.; Girault, H. H.; Hoffmannova, H.; Krtil, P.; Samec, Z. J. Am. Chem. Soc. 2004, 126, 915-919.

(37) Wandlowski, T.; Marecek, V.; Samec, Z. Electrochim. Acta 1990, 35, $1173-5$.

(38) Girault, H. H.; Schiffrin, D. J.; Smith, B. D. V. J. Colloid Interface Sci. 1984, 101, 257-266.

(39) Kakiuchi, T.; Nakanishi, M.; Senda, M. Bull. Chem. Soc. Jpn. 1988, $61,1845-1851$. 
Scheme 2. Molecular Structure of CoAP
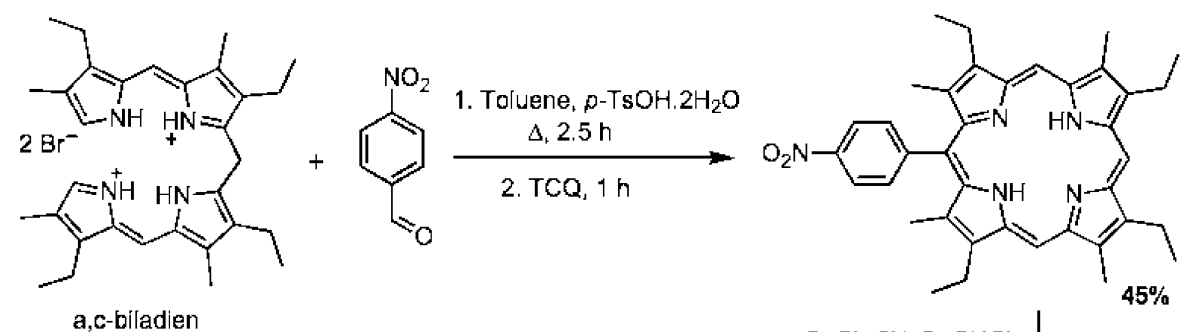

a,c-biladien

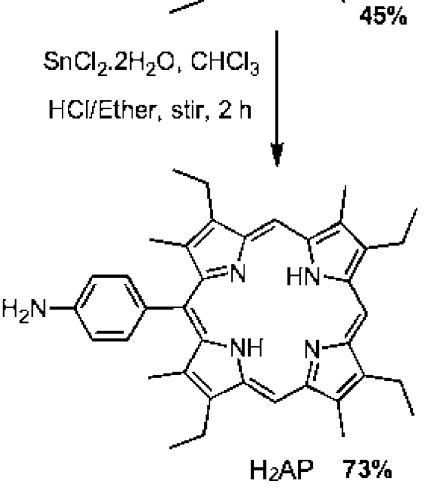

(MLP) calculated at any given point in space around a molecule using two components for the calculation, namely a fragmental system of lipophilicity and a distance function as expressed by eq 1:

$$
\operatorname{MLP}_{k}=\sum_{i=1}^{N} f_{i} \cdot \operatorname{fct}\left(d_{i k}\right)
$$

where $k$ indicates a given point in space, $i$ a given molecular fragment, $N$ the total number of fragments in the molecule, $f_{i}$ the lipophilic increment of fragment $i$, fct a distance function, and $d_{i k}$ the distance between fragment $i$ and point $k$.

Two different approaches were used to calculate the MLP, namely the CLIP software ${ }^{40,41}$ and MolCAD software ${ }^{42}$ as implemented in SYBYL 8.0. ${ }^{43}$ CLIP calculates the MLP on the water accessible surface area of a compound and displays the result as colored dots, whereas the MOLCAD calculates the MLP on its molecular surface and displays the result as a colored surface. The two approaches used different atomic fragmental systems, namely the Broto and Moreau system ${ }^{44}$ for CLIP and the Ghose and Crippen system ${ }^{4,46}$ for MOLCAD but a similar distance function reported in eq 2 :

$$
\operatorname{MLP}_{k}=\sum_{i=1}^{N} f_{i} \cdot \frac{1+\mathrm{e}^{-a b}}{1+\mathrm{e}^{a\left(d_{i k}-b\right)}}
$$

where $a$ and $b$ define respectively the decay and the distance cutoff for the sigmoidal variation of the MLP with respect to the distance $\left(d_{i k}\right)$ between the dot $k$ and the fragment $i$. A fragmental value has to be assigned to the cobalt atom not parametrized in both fragmental atomic systems. The qualitative distribution of lipophilicity on molecular surfaces was not largely affected by large

(40) Gaillard, P.; Carrupt, P. A.; Testa, B.; Boudon, A. J. Comput. Aided Mol. Des 1994, 8, 83-96.

(41) Testa, B.; Carrupt, P. A.; Gaillard, P.; Billois, F.; Weber, P. Pharm. Res. 1996, 13, 335-343.

(42) Heiden, W.; Moeckel, G.; Brickmann, J. J. Comput. Aided Mol. Des 1993, 7, 503-514.

(43) SYBYL 8.0, Tripos Associates, Inc.: St-Louis, MO, 2007.

(44) Broto, P.; Moreau, G.; Vandycke, C. Eur. J. Med. Chem. 1984, 19, $71-78$.

(45) Ghose, A. K.; Crippen, G. M. J. Comput. Chem. 1986, 7, 565-577.

(46) Viswanadhan, V. N.; Ghose, A. K.; Revankar, G. R.; Robins, R. K. J. Chem. Inf. Comput. Sci. 1989, 29, 163-172.

variations of the fragmental values for the cobalt atom defined as a polar monocentric atom. Thus, a fragmental value calibrated using atomic charges was retained for the cobalt atom.

In CLIP representations, the color coding follows a scale starting from the most polar to the most hydrophobic regions, namely red, orange, yellow, white, green, green-blue, blue. In MolCAD representations, the color coding follows a scale starting from the most polar to the most hydrophobic regions, namely blue, greenblue, green, brown, dark brown.

\section{Results and Discussion}

Synthesis of CoAP. The synthetic pathway is given in Scheme 2. First, 2,8,13,17-tetraethyl-3,7,12,18-tetramethyl-5- $p$-aminophenylporphyrin $\left(\mathrm{H}_{2} \mathrm{AP}\right)$ was synthesized by a method different from that described previously by Senge et al. ${ }^{47}$ Indeed, in this previous report, the authors were reacting $\mathrm{H}_{2} \mathrm{OEP}$ (OEP: $2,3,7,8,12,13,17,18$-octaethylporphyrin) with an excess of the organolithium reagent of $p$-bromoaniline at low temperature. In the present case, the starting material was not the corresponding free base but the 1,19-dideoxy-3,8,12,17-tetraethyl2,7,13,18-tetramethylbiladien- $a, c$-dibromide already described by our group and readily available in large amounts. ${ }^{48}$ Reaction of $p$-nitrobenzaldehyde with the $a, c$-biladien gave the corresponding nitroporphyrin which was subsequently converted to $\mathrm{H}_{2} \mathrm{AP}$ by reduction with tin(II) dichloride. CoAP was obtained by reacting $\mathrm{H}_{2} \mathrm{AP}$ with cobalt acetate tetrahydrate in a refluxing $\mathrm{CHCl}_{3} / \mathrm{MeOH}$ mixture. All compounds were fully characterized by HRMS, ${ }^{1} \mathrm{H}$ NMR, and UV-visible spectroscopy. Detailed synthetic procedures and spectroscopic data are given in the Supporting Information.

Interfacial Adsorption and Protonation of CoAP. CVs in the absence and presence of $50 \mu \mathrm{M}$ CoAP in DCE are shown in Figure 1a. The current observed at the negative and positive ends of the potential window is due to the transfer of $\mathrm{Cl}^{-}$and $\mathrm{H}^{+}$from water to DCE, respectively. Compared to the background current, the presence of CoAP resulted in a large capacitive current indicating the presence of an adsorbed layer. To verify this point, surface tension measurements were

(47) Senge, M. O.; Bischoff, I. Tetrahedron Lett. 2004, 45, 1647-1650.

(48) Tanaka, M.; Ohkubo, K.; Gros, C. P.; Guilard, R.; Fukuzumi, S. J. Am. Chem. Soc. 2006, 128, 14625-14633. 

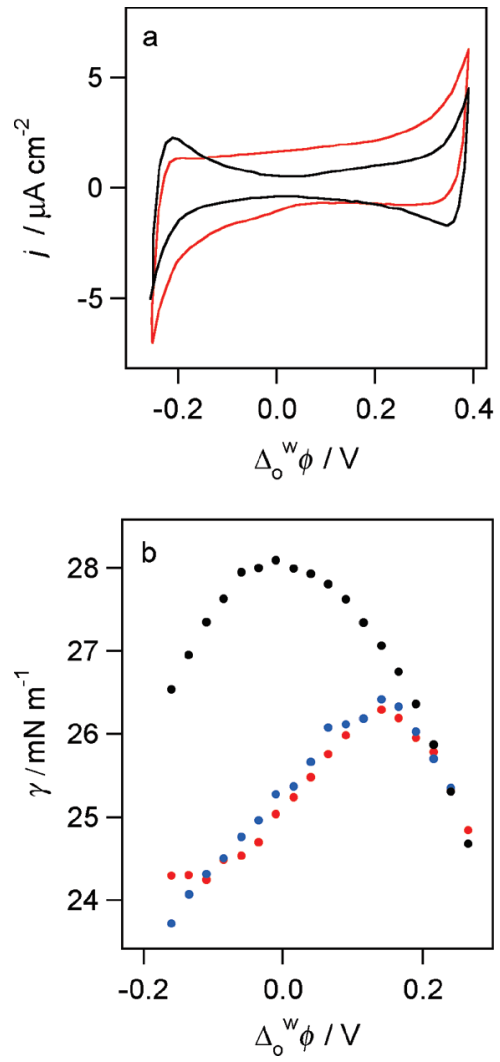

Figure 1. (a) CVs in the absence ( $x=0$, black line) and presence $(x=50$ $\mu \mathrm{M}$, red line) of CoAP in DCE using Cell 1: $y=0$ (no ferrocene), $\mathrm{pH} 2$, scan rate $0.05 \mathrm{~V} \mathrm{~s}^{-1}$. (b) Electrocapillary curves in the absence and presence of CoAP using Cell 2: $z=0$ (black) and $50 \mu \mathrm{M}$ (red). The measurement started from the negative potential, and the electrocapillary curve obtained in the reverse direction (blue) is the same.

performed using a video-image pendant-drop method, ${ }^{38,39}$ and the obtained electrocapillary curves are displayed in Figure 1b. The parabolic shape of the electrocapillary curve in the absence of CoAP is characteristic of two back-to-back Gouy-Chapman diffuse layers without any specific adsorption of electrolyte ions. ${ }^{49}$ The addition of CoAP in DCE results in a significant decrease in the surface tension primarily at potentials negative to the electrocapillary maximum (potential of zero charge, $p z c$ ), indicating the adsorption of CoAP species. Toward positive potentials, the surface tension starts to increase and finally overlaps with the surface tension of the background electrolytes. It has to be mentioned that the measurements started from negative potentials, but that surface tension data obtained in the reverse direction are practically identical.

The adsorption of CoAP stems from its amphiphilicity as illustrated in Figure 2, with the amino group as the hydrophilic moiety and the metalated ring as the lipophilic part. The interfacial activity of CoAP is also related to its acid-base properties and to the concentration of protons on the aqueous side of the interface, which increases at potentials positive to the $p z c$. Thus, the significant decrease of the surface tension at very negative potentials can be attributed to the adsorption of neutral CoAP and oxygenated CoAP, $\left(\mathrm{Co}-\mathrm{O}_{2}\right) \mathrm{AP}$, at the interface. As shown below, $\mathrm{CoAP}$ and $\left(\mathrm{Co}-\mathrm{O}_{2}\right) \mathrm{AP}$ coexist in the stock sample both in solid and in solution. When scanning the potential more positive than the $p z c$, the proton concentration at the interface is increased and the adsorbed

(49) Samec, Z. Chem. Rev. 1988, 88, 617-32.
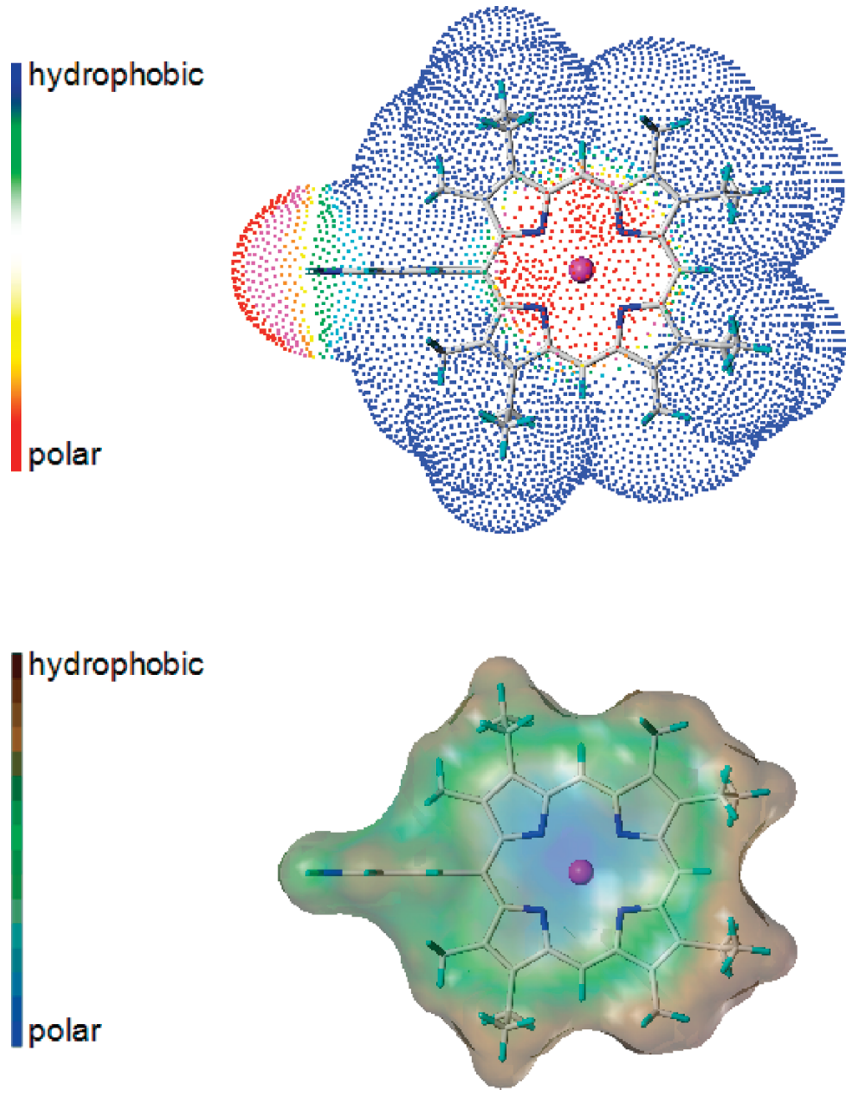

Figure 2. Lipophilicity maps for CoAP using CLIP (top) and MOLCAD (bottom).

$\left(\mathrm{Co}-\mathrm{O}_{2}\right)$ AP can be protonated to form $\left[\left(\mathrm{Co}-\mathrm{O}_{2} \mathrm{H}\right) \mathrm{AP}\right]^{+}$by protonation of the bound oxygen, The protonation of the amino group usually takes place at much more positive potentials or at much lower $\mathrm{pH}$ values. ${ }^{50}$ The adsorbed $\left[\left(\mathrm{Co}-\mathrm{O}_{2} \mathrm{H}\right) \mathrm{AP}\right]^{+}$will desorb to the organic phase at a positive potential, leading to a decrease of interfacial coverage of $\left[\left(\mathrm{Co}-\mathrm{O}_{2} \mathrm{H}\right) \mathrm{AP}\right]^{+}$and an increase of the surface tension. The surface tension data thereby point to the formation of $\left[\left(\mathrm{Co}-\mathrm{O}_{2} \mathrm{H}\right) \mathrm{AP}\right]^{+}$that undergoes an electrochemical ion transfer reaction from the adsorbed state:

$$
\begin{gathered}
\left(\mathrm{Co}-\mathrm{O}_{2}\right) \mathrm{AP}_{(\mathrm{ads})}+\mathrm{H}_{(\mathrm{W})}^{+} \rightarrow\left[\left(\mathrm{Co}-\mathrm{O}_{2} \mathrm{H}\right) \mathrm{AP}\right]_{(\mathrm{ads})}^{+} \\
{\left[\left(\mathrm{Co}-\mathrm{O}_{2} \mathrm{H}\right) \mathrm{AP}\right]_{(\mathrm{ads})}^{+} \rightarrow\left[\left(\mathrm{Co}-\mathrm{O}_{2} \mathrm{H}\right) \mathrm{AP}\right]_{(\mathrm{DCE})}^{+}}
\end{gathered}
$$

Here, the species in water, in DCE and adsorbed at the interface are denoted as (w), (DCE), and (ads), respectively. It is well-known that cobalt porphyrins are able to coordinate $\mathrm{O}_{2}$, thereby forming a superoxide-like structure, which can be protonated to produce hydroperoxyl radicals. ${ }^{51,52}$

Figure 3 a shows that the surface tension decreases considerably with increasing the concentration of CoAP in DCE. This dependence can be used to evaluate the surface excess concentration of CoAP and to determine the adsorption isotherm on

(50) Velazquez-Manzanares, M.; Schifferin, D. J. Electrochim. Acta 2004, 49, 4651-4658.

(51) Jones, R. D.; Summerville, D. A.; Basolo, F. Chem. Rev. 1979, 79, 139-179.

(52) Zhao, Z.; Ozoemena, K. I.; Maree, D. M.; Nyokong, T. Dalton Trans. 2005, 1241-1248. 

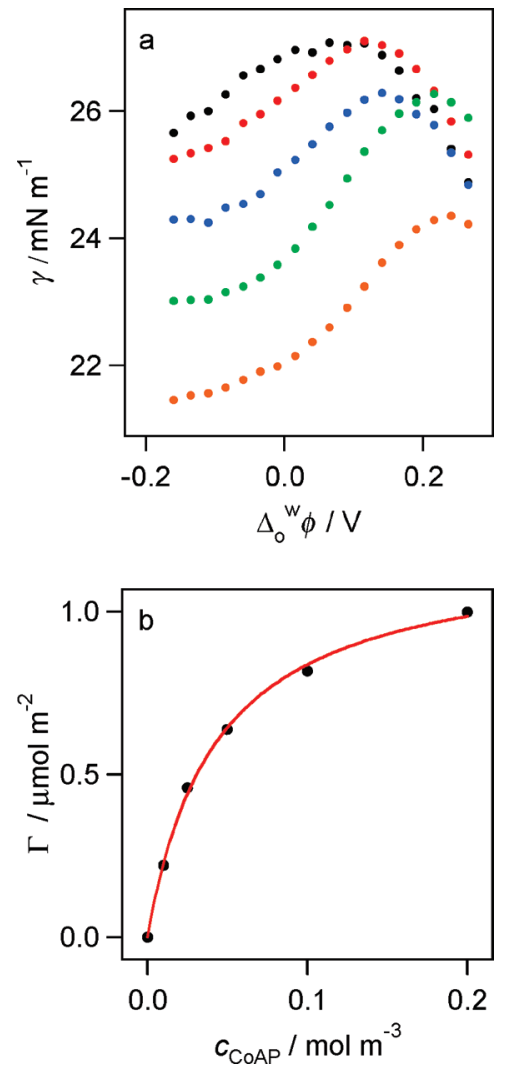

Figure 3. (a) Electrocapillary curves at various concentrations of CoAP using Cell 2: $z=10 \mu \mathrm{M}$ (black), $25 \mu \mathrm{M}$ (red), $50 \mu \mathrm{M}$ (blue), $100 \mu \mathrm{M}$ (green), and $200 \mu \mathrm{M}$ (brown). The measurements started from the negative potential. (b) CoAP adsorption isotherm constructed with the surface tension data at $-0.10 \mathrm{~V}$. The red line corresponds to a fit to the Langmuir isotherm.

the basis of the Gibbs adsorption equation (see the derivation in the Supporting Information): ${ }^{53}$

$$
\begin{aligned}
\Gamma_{\mathrm{CoAP}}+\Gamma_{\left(\mathrm{Co}-\mathrm{O}_{2}\right) \mathrm{AP}}+\Gamma_{\left[\left(\mathrm{Co}-\mathrm{O}_{2} \mathrm{H}\right) \mathrm{AP}\right]^{+}}= \\
-\frac{1}{R T}\left(\frac{\partial \gamma}{\partial \ln c_{\mathrm{CoAP}}}\right)_{T, P, \Delta_{0}^{\mathrm{w}} \phi, \mu_{i} \neq \mu_{\mathrm{CoAP}}}
\end{aligned}
$$

where $c_{\mathrm{CoAP}}$ is the bulk concentration of CoAP in DCE and $\Gamma_{i}$ $\left(i=\mathrm{CoAP},\left(\mathrm{Co}-\mathrm{O}_{2}\right) \mathrm{AP}\right.$ and $\left.\left[\left(\mathrm{Co}-\mathrm{O}_{2} \mathrm{H}\right) \mathrm{AP}\right]^{+}\right)$represent the respective surface excess concentration. In terms of eq 5 , the surface coverage of CoAP species has three contributions. At positive potentials $\left[\left(\mathrm{Co}-\mathrm{O}_{2} \mathrm{H}\right) \mathrm{AP}\right]^{+}$is formed, the deconvolution of this contribution from two others is difficult because both the adsorption and transfer processes are involved. However, at potentials more negative than $-0.1 \mathrm{~V}$, the adsorption of neutral CoAP and $\left(\mathrm{Co}-\mathrm{O}_{2}\right) \mathrm{AP}$ is dominant. Assuming, for simplicity, that CoAP and $\left(\mathrm{Co}-\mathrm{O}_{2}\right)$ AP have the same molecular structure and interfacial affinity, the concentration dependence of the surface excess concentration evaluated at $-0.1 \mathrm{~V}$ (shown in Figure 3b), can be fitted to a Langmuir isotherm:

$$
\Gamma_{\mathrm{CoAP}}=\Gamma_{\mathrm{CoAP}}^{*} \frac{\beta c_{\mathrm{CoAP}}}{1+\beta c_{\mathrm{CoAP}}}
$$

where $\Gamma_{\text {CoAP }}^{*}$ and $\beta$ are the maximum surface excess concentration and Langmuir adsorption coefficient of CoAP, respectively.

(53) Samec, Z.; Trojanek, A.; Girault, H. H. Electrochem. Commun. 2003, $5,98-103$.
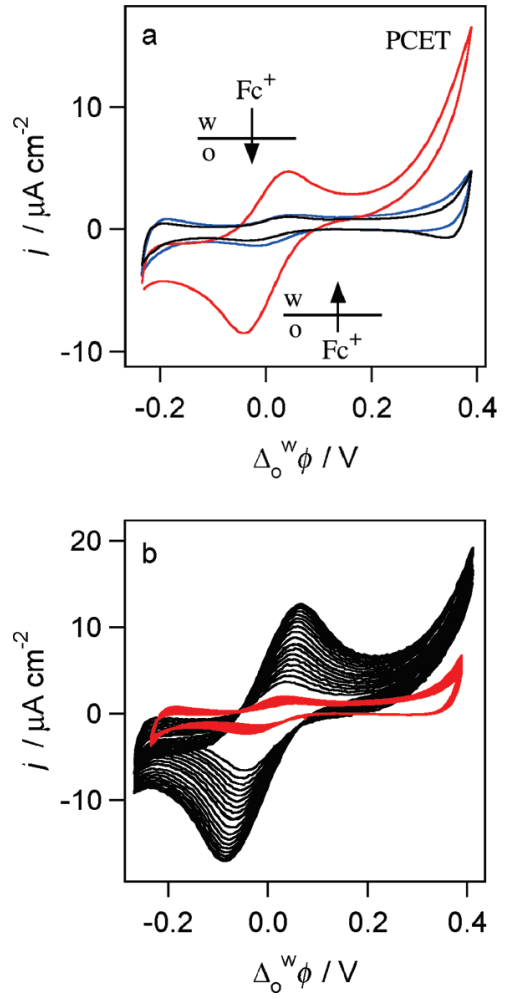

Figure 4. (a) CVs in the presence of only $5 \mathrm{mM} \mathrm{Fc}$ (black line, $x=0, y$ $=5 \mathrm{mM})$ and in the presence of both $5 \mathrm{mM} \mathrm{Fc}$ and $25 \mu \mathrm{M} \mathrm{CoAP}(x=25$ $\mu \mathrm{M}, y=5 \mathrm{mM}$ ) in DCE (red line) using Cell 1: $\mathrm{pH} 2$. The blue line was obtained under anaerobic conditions but others same as the red line, scan rate $0.05 \mathrm{~V} \mathrm{~s}^{-1}$; (b) 20 cycles of CVs in the presence of both $5 \mathrm{mM} \mathrm{Fc}$ and $25 \mu \mathrm{M}$ CoAP using Cell $1(x=25 \mu \mathrm{M}, y=5 \mathrm{mM})$ under aerobic (black lines) and anaerobic (red lines) conditions, scan rate $0.05 \mathrm{~V} \mathrm{~s}^{-1}$.

The fitting yields $\Gamma_{\text {CoAP }}^{*}=(1.03 \pm 0.04) \times 10^{-6} \mathrm{~mol} \mathrm{~m}^{-2}$ and $\beta=(3.29 \pm 0.04) \times 10^{4} \mathrm{M}^{-1}$. From $\Gamma_{\text {CoAP }}^{*}$, the area per molecule occupied amounts $161 \AA^{2}$, which suggests that adsorbed CoAP species take an orientation normal to the interface with the hydrophilic amino group toward the aqueous phase.

Interfacial Proton-Coupled Oxygen Reduction Catalyzed by CoAP. Figure 4 a compares the CVs obtained under different experimental conditions. First, in the presence of only $\mathrm{Fc}$ in DCE under aerobic conditions a small voltammetric wave with a half-wave potential at $\Delta_{\mathrm{o}}^{\mathrm{w}} \phi_{1 / 2}=0 \mathrm{~V}$ was observed, which corresponds to the transfer of ferrocenium $\left(\mathrm{Fc}^{+}\right)$produced by a slow oxidation of $\mathrm{Fc}$ in air of the stock solution. ${ }^{33,34}$ Also shown above in Figure 1a is that in the presence of only CoAP in DCE under aerobic conditions only an overall capacitive current signal was observed. However, when both Fc and CoAP were dissolved in DCE, an irreversible positive current signal appeared in the positive potential range. A control experiment under anaerobic conditions showed that this current signal did not appear (blue line in Figure 4a). These facts suggest that $\mathrm{CoAP}, \mathrm{O}_{2}$, and $\mathrm{Fc}$ must be present at the same time to observe this signal. Therefore, similar to that observed with cobalt porphine, ${ }^{33}$ this irreversible current signal corresponds to a proton-coupled oxygen reduction process catalyzed by CoAP. This process produces $\mathrm{Fc}^{+}$, thus accounting for the significant increment of the $\mathrm{Fc}^{+}$transfer current wave located at $0 \mathrm{~V}$ as shown in Figure $4 \mathrm{a}$. Indeed, the standard redox potential for $\mathrm{Co}^{\mathrm{III}} \mathrm{AP}^{+} / \mathrm{Co}^{\mathrm{II}} \mathrm{AP}$ is equal to $0.69 \mathrm{~V}$ vs SHE (see Supporting Information, Figure S-1) more positive than that of Fc equal to $0.64 \mathrm{~V}$ vs SHE. In 


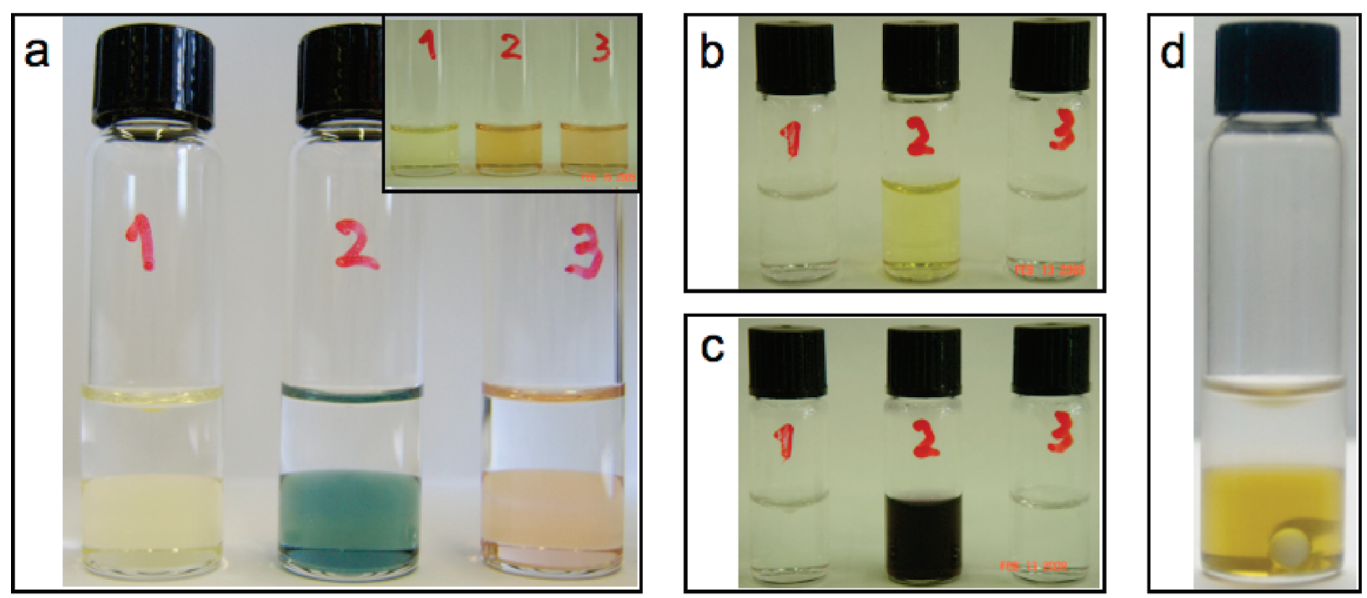

Figure 5. (a) Photographs of two-phase reactions. The composition of the top aqueous phase is the same for three flasks: $5 \mathrm{mM} \mathrm{LiTB}+10 \mathrm{mM} \mathrm{HCl}$. The DCE phase contains: $1 \mathrm{mM} \mathrm{Fc}+5 \mathrm{mM}$ BATB (flask 1), $1 \mathrm{mM} \mathrm{Fc}+20 \mu \mathrm{M}$ CoAP $+5 \mathrm{mM}$ BATB (flask 2), and $20 \mu \mathrm{M} \mathrm{CoAP}+5 \mathrm{mM}$ BATB (flask 3 ). The inset in (a) shows the colors of three DCE solutions before contact with the water solution; (b) isolated top aqueous solutions with added excess $\mathrm{NaI}$; (c) further addition of starch to the flasks shown in (b); (d) 4-h two-phase reaction in the glovebox with the same solution composition as that of flask 2 in (a).

fact, when cycling the potential to the positive values repeatedly, more $\mathrm{Fc}^{+}$will be produced, leading to a continuous increase of the $\mathrm{Fc}^{+}$transfer current scan after scan (black lines in Figure 4b). In contrast, under anaerobic conditions, the $\mathrm{Fc}^{+}$transfer current wave did not increase with repeated potential scans (red lines in Figure 4b).

The reduction of $\mathrm{O}_{2}$ by $\mathrm{Fc}$ was also investigated by socalled shake-flask experiments performed as reported previously. ${ }^{33}$ The Galvani potential difference across the water/ DCE interface was polarized at a very positive value of 0.54 $\mathrm{V}$ by two salts, LiTB and BATB, having a common anion of $\mathrm{TB}^{-}$. At such potential values, protons are transferred from water to DCE by the lipophilic aqueous $\mathrm{TB}^{-}$ions acting as a proton pump dragging with them protons as they transfer to the organic phase. Results of the shake-flask experiments are shown in Figure 5. As shown in Figure 5a, $10 \mathrm{mM} \mathrm{HCl}$ was present in water in all three flasks, and the DCE phase contained only $1 \mathrm{mM} \mathrm{Fc}$ in flask 1 , only $20 \mu \mathrm{M}$ CoAP in flask 3 , and both in flask 2. It was observed that the DCE phase in flask 2 changed its color from pink (inset in (a)) to dark green immediately after being put in contact with the water solution. In contrast, the DCE phase in the other two flasks remained the same. The two phases were then separated from each other for further spectroscopic and colorimetric tests.

First, UV-visible spectra of the separated DCE solutions were measured, as shown in Figure 6a. The formation of $\mathrm{Fc}^{+}$ in the DCE solution from flask 2 was revealed, and the absorption band with a maximum at $620 \mathrm{~nm}$ represents its signature (blue line). The color change is thus due to the oxidation of $\mathrm{Fc}$ to $\mathrm{Fc}^{+}$, and the color of DCE phase in the flask 2 reflects a mixed color of green $\mathrm{Fc}^{+}$and pink CoAP. In contrast, in the presence of Fc only in DCE (flask 1) no $\mathrm{Fc}^{+}$was detected, because no changes in color and in the absorption spectrum (red line compared to full black line) were observed. On the other hand, when only CoAP is present in DCE (flask 3), changes in the absorption spectrum (green line compared to dotted black line) due to the oxidation of $\mathrm{Co}^{\mathrm{II}} \mathrm{AP}$ to $\mathrm{Co}^{\mathrm{III}} \mathrm{AP}^{+}$ and the protonation of the amino group (see Supporting Information, Figure S-2) were observed. As for the isolated aqueous solutions from three flasks, excess $\mathrm{NaI}$ equivalent to
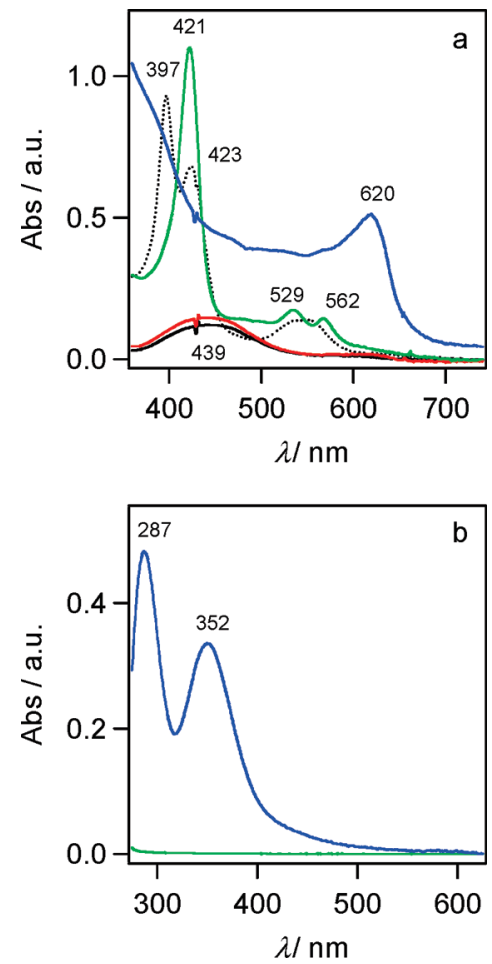

Figure 6. (a) Absorption spectra of the DCE phases shown in Figure 5a: flask 1 (red), flask 2 (blue), and flask 3 (green), and of a fresh $1 \mathrm{mM} \mathrm{Fc}$ (full black) and a fresh $20 \mu \mathrm{M}$ CoAP (dotted black); (b) UV-visible spectra of the 10 times diluted aqueous solutions shown in Figure 5b: flask 2 (blue) and flask 1 and 3 (green).

0.1 M was added. It was observed that the color from flask 2 changed from colorless to yellow as illustrated in Figure 5b. As shown previously, this color change can be due to the presence of $\mathrm{H}_{2} \mathrm{O}_{2}$ in the solution. ${ }^{54} \mathrm{H}_{2} \mathrm{O}_{2}$ is a strong oxidant that can oxidize $\mathrm{I}^{-}$to $\mathrm{I}_{3}{ }^{-}$, which appears yellow and displays two absorption bands $\left(\lambda_{\max }=286\right.$ and $\left.352 \mathrm{~nm}\right)$ as shown by

(54) Su, B.; Nia, R. P.; Li, F.; Hojeij, M.; Prudent, M.; Corminboeuf, C.; Samec, Z.; Girault, H. H. Angew. Chem., Int. Ed. 2008, 47, 46754678. 
the blue line in Figure 6b. Additionally, $\mathrm{I}_{3}{ }^{-}$changes its color to very brown when meeting with aqueous soluble starch (Figure 5c). In contrast, no $\mathrm{H}_{2} \mathrm{O}_{2}$ was detected at all in the aqueous solutions from flasks 1 and 3 , as seen both from the colorimetric responses and the UV-visible spectra (green curve in Figure $6 b)$.

The above experimental facts clearly demonstrated that $\mathrm{H}_{2} \mathrm{O}_{2}$ and $\mathrm{Fc}^{+}$were produced in water and DCE, respectively, only when both $\mathrm{Fc}$ and CoAP were present (flask 2). A control experiment under anaerobic conditions (Figure 5d) showing that the DCE solution containing Fc and CoAP did not change its color even after $3 \mathrm{~h}$, further proving the reduction of $\mathrm{O}_{2}$ to $\mathrm{H}_{2} \mathrm{O}_{2}$ by Fc catalyzed by CoAP. Similar to other conventional cobalt porphyrins, CoAP activates $\mathrm{O}_{2}$ by the formation of a superoxidelike intermediate with $\mathrm{O}_{2}$ coordinated to cobalt, which can be seen clearly in the UV-visible spectrum of CoAP. As shown in Figure 6a, a freshly prepared CoAP solution displays two Soret bands $\left(\lambda_{\max }=397\right.$ and $\left.423 \mathrm{~nm}\right)$ and a broad convoluted Q-band $\left(\lambda_{\max }=552 \mathrm{~nm}\right)$. The second Soret band reflects that the solution contains $\left(\mathrm{Co}-\mathrm{O}_{2}\right) \mathrm{AP}$ in which the electron delocalization from $\mathrm{Co}(\mathrm{II})$ to $\mathrm{O}_{2}$ occurs, leading to a bathochromic shift of both Soret and $\mathrm{Q}$ bands in the UV-visible spectrum. ${ }^{51,52}$

Mechanism and Thermodynamic Analysis. An overall reaction of oxygen reduction with Fc catalyzed by CoAP is:

$$
2 \mathrm{Fc}_{(\mathrm{DCE})}+2 \mathrm{H}_{(\mathrm{W})}^{+}+\mathrm{O}_{2(\mathrm{DCE})} \stackrel{\mathrm{CoAP}}{\longrightarrow} 2 \mathrm{Fc}_{(\mathrm{DCE})}^{+}+\mathrm{H}_{2} \mathrm{O}_{2(\mathrm{~W})}
$$

A corresponding reaction scheme involving the adsorption of $\left(\mathrm{Co}-\mathrm{O}_{2}\right) \mathrm{AP}$ (dashed line), proton-coupled oxygen reduction (solid line), and regeneration of $\mathrm{CoAP}^{+}$by $\mathrm{Fc}$ (dotted line) is illustrated in Scheme 3. These steps can be expressed as follows:

$$
\mathrm{CoAP}_{(\mathrm{DCE})}+\mathrm{O}_{2(\mathrm{DCE})} \rightarrow\left(\mathrm{Co}-\mathrm{O}_{2}\right) \mathrm{AP}_{(\mathrm{DCE})}
$$

$$
\begin{aligned}
&\left(\mathrm{Co}-\mathrm{O}_{2}\right) \mathrm{AP}_{(\mathrm{DCE})} \rightarrow\left(\mathrm{Co}-\mathrm{O}_{2}\right) \mathrm{AP}_{(\mathrm{ads})} \\
&\left(\mathrm{Co}-\mathrm{O}_{2}\right) \mathrm{AP}_{(\mathrm{ads})}+2 \mathrm{H}_{(\mathrm{W})}^{+}+\mathrm{Fc}_{(\mathrm{DCE})} \rightarrow \mathrm{CoAP}_{(\mathrm{DCE})}^{+}+ \\
& \mathrm{Fc}_{(\mathrm{DCE})}^{+}+\mathrm{H}_{2} \mathrm{O}_{2(\mathrm{~W})} \\
& \mathrm{CoAP}_{(\mathrm{DCE})}^{+}+\mathrm{Fc}_{(\mathrm{DCE})} \rightarrow \mathrm{CoAP}_{(\mathrm{DCE})}+\mathrm{Fc}_{(\mathrm{DCE})}^{+}
\end{aligned}
$$

In terms of this scheme, the Nernst equation for the overall process is: ${ }^{33}$

$$
\begin{aligned}
& \Delta_{\mathrm{o}}^{\mathrm{w}} \phi_{\mathrm{et}}=\Delta_{\mathrm{o}}^{\mathrm{w}} \phi_{\mathrm{et}}^{0}+\frac{R T \ln 10}{F} \mathrm{pH}+ \\
& \frac{R T}{2 F} \ln \left[\left(\frac{a_{\mathrm{Fc}^{+}}^{\mathrm{o}}}{a_{\mathrm{Fc}}^{\mathrm{o}}}\right)\left(\frac{a_{\mathrm{CoAP}}^{\mathrm{o}}}{a_{\mathrm{CoAP}}^{\mathrm{o}}}\right)\left(\frac{p^{0}}{f_{\mathrm{O}_{2}}}\right) a_{\mathrm{H}_{2} \mathrm{O}_{2}}^{\mathrm{w}}\right]
\end{aligned}
$$

where $a_{i}^{\alpha}(\alpha=$ o or $\mathrm{w})$ represents the activity of species $i . p^{0}$ and $f_{\mathrm{O}_{2}}$ are the standard pressure and the fugacity of oxygen. $\Delta_{\mathrm{o}}^{\mathrm{w}} \phi_{\mathrm{et}}^{0}$ represents the standard Galvani potential difference given by: ${ }^{33}$

$$
\Delta_{\mathrm{o}}^{\mathrm{w}} \phi_{\mathrm{et}}^{0}=\frac{1}{2}\left[E_{\mathrm{CoAP}^{+} / \mathrm{CoAP}}^{0}\right]_{\mathrm{SHE}}^{\mathrm{o}}+\frac{1}{2}\left[E_{\mathrm{Fc}^{+} / \mathrm{Fc}}^{0}\right]_{\mathrm{SHE}}^{\mathrm{o}}-\left[E_{\mathrm{O}_{2} / \mathrm{H}_{2} \mathrm{O}_{2}}^{0}\right]_{\mathrm{SHE}}^{\mathrm{w}}
$$

where $\left[E_{\mathrm{CoAP}}^{0} / \mathrm{CoAP}\right]_{\mathrm{SHE}}^{0},\left[E_{\mathrm{Fc}}^{0} / \mathrm{Fc}\right]_{\mathrm{SHE}}^{0}$, and $\left[E_{\mathrm{O}_{2} / \mathrm{H}_{2} \mathrm{O}_{2}}^{0}\right]_{\mathrm{SHE}}^{\mathrm{W}}$ denote the standard redox potentials of the $\mathrm{CoAP}^{+} / \mathrm{CoAP}$ and $\mathrm{Fc}^{+} / \mathrm{Fc}$ couples in DCE and the $\mathrm{O}_{2} / \mathrm{H}_{2} \mathrm{O}_{2}$ couple in water, respectively, all with respect to the aqueous standard hydrogen electrode (SHE). Equation 12 predicts the $\mathrm{pH}$ dependence of the redox Galvani potential difference, which is corroborated by the shift of the current signal with $\mathrm{pH}$ by about $60 \mathrm{mV} / \mathrm{pH}$ as shown in Figure 7. Equations 12 and 13 also indicate a dependence on the standard redox potential of the organic electron donor. When $\mathrm{Fc}$ is replaced either by a stronger electron donor, DFc, or by a weaker one, FcCA, the onset potential of the irreversible current shifts to negative and positive potentials, respectively, as displayed in Figure 8a. A negative shift of $45 \mathrm{mV}$ was experimentally observed for DFc with a logarithmic plot (Figure

Scheme 3. Catalysis Mechanism

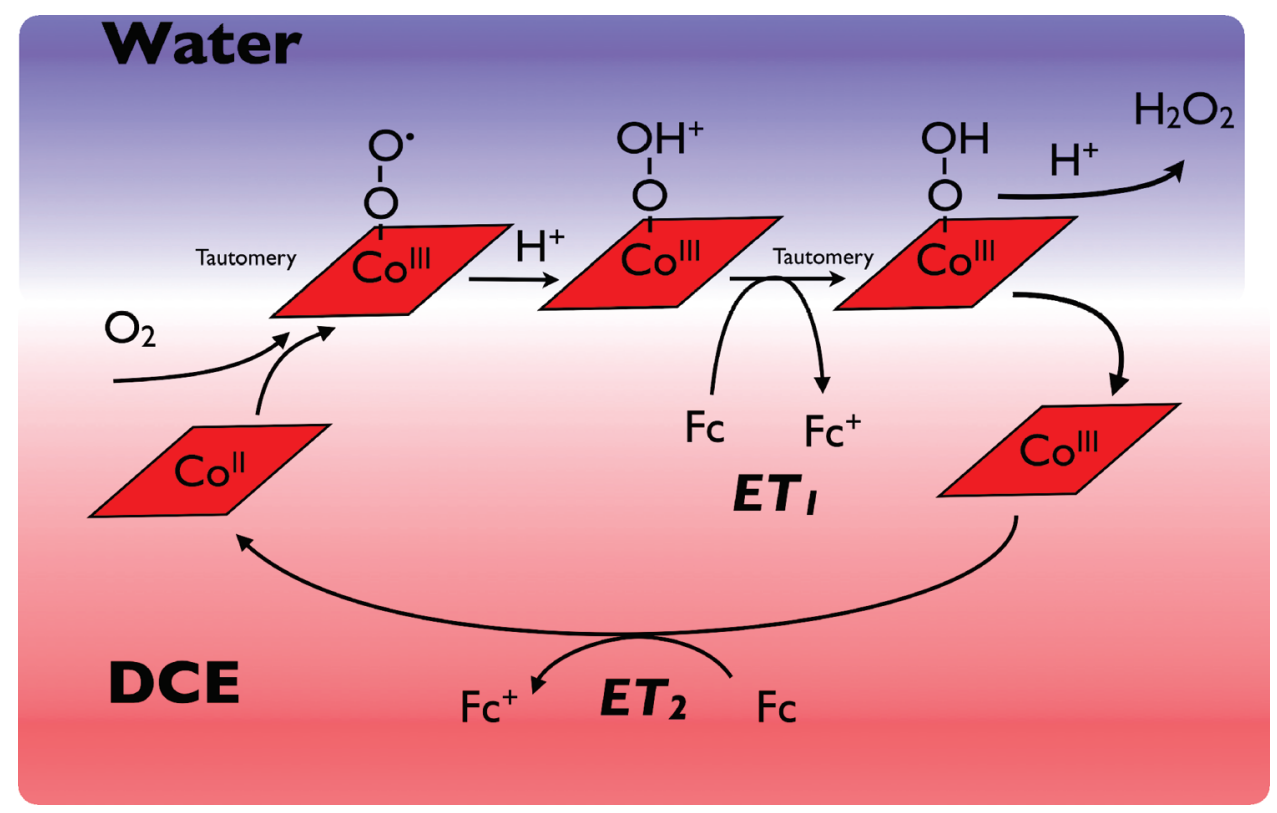




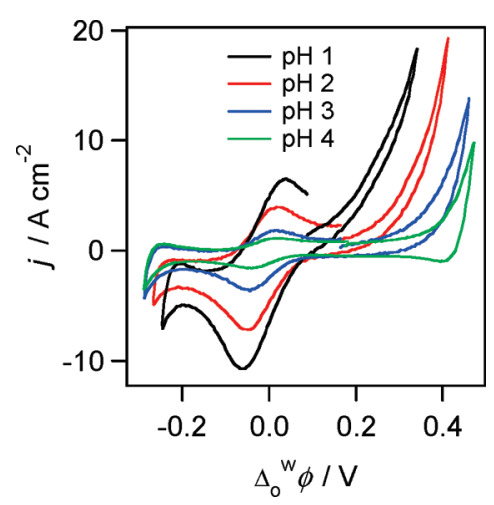

Figure 7. CVs in the presence of both $5 \mathrm{mM} \mathrm{Fc}$ and $25 \mu \mathrm{M}$ CoAP $(x=$ $25 \mu \mathrm{M}, y=5 \mathrm{mM}$ ) using Cell 1 at various $\mathrm{pH}$, scan rate $0.02 \mathrm{~V} \mathrm{~s}^{-1}$.
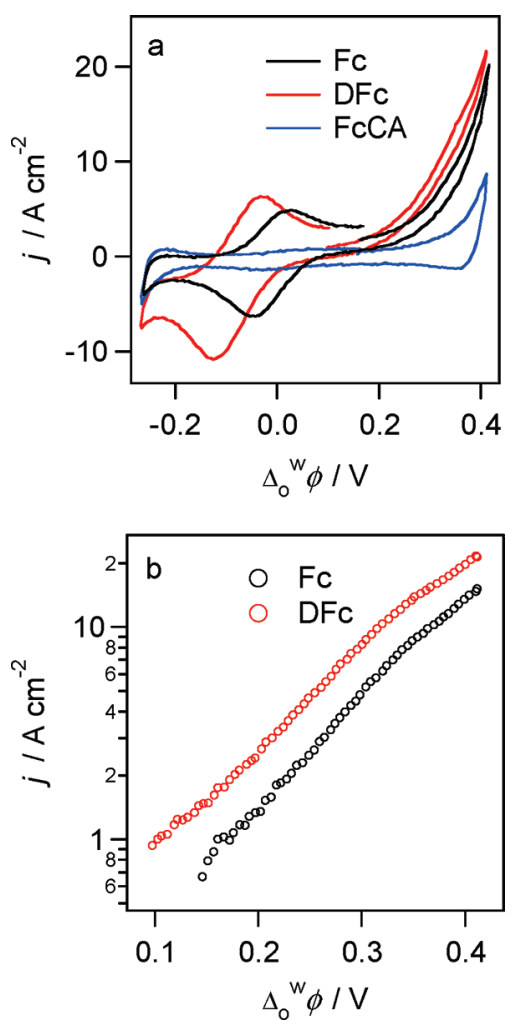

Figure 8. (a) $\mathrm{CVs}$ in the presence of $25 \mu \mathrm{M}$ CoAP and $5 \mathrm{mM}$ Fc (black), $\mathrm{DFc}$ (red), and FcCA (blue) using Cell $1(x=25 \mu \mathrm{M}, y=5 \mathrm{mM})$, scan rate $0.02 \mathrm{~V} \mathrm{~s}^{-1}$. (b) Logarithmic plots of the catalytic current in the forward scan for Fc (black) and DFc (red).

$8 b$ ), which is in agreement with the theoretical prediction of eqs 12 and 13.

Finally, it should be mentioned that the proton-coupled oxygen reduction catalyzed by CoAP is an interfacial process, as voltammetry only measures interfacial charge transfer reactions. The interfacial affinity of CoAP accounts for the excellent catalytic activity observed by measuring the PCET current. Indeed, it is much more efficient than cobalt porphine and 2,3,7,8,12,13,17,18-octaethylporphyrin cobalt(II) (CoOEP) which are not amphiphilic (see Supporting Information, Figure S-3). ${ }^{33,35}$ The comparison with CoOEP highlights in particular the role of the amphiphilicity of the catalyst as both CoAP and CoOEP have the same redox potential for the first oxidation $(0.69 \mathrm{~V}$ vs SHE).

\section{Conclusions}

In summary, the catalytic effect of (2,8,13,17-tetraethyl3,7,12,18-tetramethyl-5-p-amino-phenylporphyrin) cobalt(II) (CoAP) on the proton-coupled oxygen reduction by $\mathrm{Fc}$ was studied at a water/DCE interface. CoAP serves as a redox catalyst like conventional monomeric cobalt porphyrins, activating $\mathrm{O}_{2}$ for the reduction to $\mathrm{H}_{2} \mathrm{O}_{2}$. On the other hand, since CoAP has a strong interfacial affinity due to the amino group at a meso position, it presents an excellent electrocatalytic activity over other cobalt porphyrins that do not adsorb at the water/DCE interface such as the nonamphiphilic analogue CoOEP. This study demonstrates the concept of interfacial molecular electrocatalysis for the reduction of oxygen combining the use of molecular catalysts under electrochemical control.

In a general manner, the advantage of using amphiphilic molecular catalysts at polarized liquid-liquid interfaces stems from the fact that catalysts may be oxidized and destroyed during the course of the reaction by spurious radical side reactions. The degraded catalysts are likely to lose their amphiphilicity and to desorb from the interface where new catalysts will be able to adsorb from the bulk. This is similar to what happens in natural photosystems, in which the molecular catalysts have a finite lifetime and are replaced permanently by freshly synthesized ones.

Acknowledgment. This work was supported by EPFL, the Swiss Natural Science Foundation (FNRS 200020-116588), European Union COST Action (D36/007/06), the Grant Agency of the Czech Republic (No. 203/07/1257), CNRS (UMR 5260), and the Scientific and Research Council of Turkey (TUBITAK) under the 2212-PhD Scholarship Program.

Supporting Information Available: Porphyrin synthesis procedures, measurements of redox potentials of CoAP, math derivation of surface excess concentration (eq 5), spectrophotometric titration of CoAP with TFA, and the comparison of catalysis of CoAP with other cobalt porphyrins. This material is available free of charge via the Internet at http://pubs.acs.org.

JA908488S 